\title{
Symptom burden in stable COPD patients with moderate or severe airflow limitation
}

\author{
Jeanette Eckerblad, Kristina Tödt, Per Jakobsson, Mitra Unosson, Elisabeth Skargren, M. \\ Kentsson and K. Theander
}

\section{Linköping University Post Print}

\section{Tweet}

N.B.: When citing this work, cite the original article.

Original Publication:

Jeanette Eckerblad, Kristina Tödt, Per Jakobsson, Mitra Unosson, Elisabeth Skargren, M. Kentsson and K. Theander, Symptom burden in stable COPD patients with moderate or severe airflow limitation, 2014, Heart \& Lung, (43), 4, 351-357.

http://dx.doi.org/10.1016/j.hrtlng.2014.04.004

Copyright: Elsevier http://www.elsevier.com/

Postprint available at: Linköping University Electronic Press http://urn.kb.se/resolve?urn=urn:nbn:se:liu:diva-109384 


\section{Symptom burden in stable COPD patients with moderate or severe airflow limitation}

ECKERBLAD J., RN ${ }^{1}$, TÖDT K., RPt ${ }^{1,2}$, JAKOBSSON P., PhD MD ${ }^{2}$, UNOSSON M., PhD RN ${ }^{1}$, SKARGREN E ${ }^{3}$., PhD RPt, KENTSSON M., MD ${ }^{4}$, THEANDER K., PhD RN ${ }^{5,6}$.

${ }^{1}$ Department of Social and Welfare Studies, Faculty of Health Sciences, Linkoping University, 58185 Linkoping, Sweden

${ }^{2}$ Department of Pulmonary Medicine, University Hospital, 58185 Linkoping, Sweden,

${ }^{3}$ Department of Medicine and Health Sciences, Faculty of Health Sciences, Linkoping University, 58185 Linkoping Sweden,

${ }^{4}$ Department of Pulmonary Medicine, Ryhov Hospital, Jonkoping, S-551 85 Jonkoping, Sweden,

${ }^{5}$ Faculty of Health, Science and Technology, Department of Health Sciences, Nursing, Karlstad University, 65637 Karlstad, Sweden,

${ }^{6}$ Primary Care Research Unit, Varmland County Council, Karlstad

Corresponding author: Jeanette Eckerblad

Mail to: Jeanette.eckerblad@liu.se

Linkoping university / ISV

60174Norrkoping

Phone:+46 11363575 
Accepted for publication in Heart and Lung April 2014

Running head: Symptom burden in moderate or severe airflow limitations

\title{
Symptom burden in stable COPD patients with moderate or severe airflow limitations.
}

\author{
Abstract \\ Objectives. To describe a multidimensional symptom profile in patients with stable chronic \\ obstructive pulmonary disease (COPD) and determine whether symptom experience differed \\ between patients with moderate or severe airflow limitations.
}

Background. Patients with severe airflow limitation experience numerous symptoms, but little is known regarding patients with moderate airflow limitation.

Methods. A multidimensional symptom profile (Memorial Symptom Assessment Scale) was assessed in 42 outpatients with moderate and 49 with severe airflow limitations.

Results. The mean number of symptoms in the total sample was $7.9( \pm 4.3)$ with no difference between patients with moderate and severe airflow limitations. The most prevalent symptoms with the highest MSAS symptom burden scores were shortness of breath, dry mouth, cough, sleep problems, and lack of energy in both groups.

Conclusions. Patients with moderate or severe airflow limitations experience multiple symptoms with high severity and distress. An assessment of their multidimensional symptom profile might contribute to better symptom management.

Keywords: chronic obstructive pulmonary disease, symptom assessment, symptom experience, respiratory nursing 


\section{INTRODUCTION}

Chronic obstructive pulmonary disease (COPD) is a common disease worldwide and is predicted to become the third-leading cause of death by $2020^{1}$. Patients with COPD experience a slow decline in lung function and health over time ${ }^{2}$. In its early stages, COPD is usually not recognized, diagnosed, or treated, as many patients seek healthcare attention only after substantial damage has occurred to the lungs, and related symptoms are present ${ }^{3}$. In addition, COPD is often associated with co-morbidities that may produce single or multiple symptoms ${ }^{4}$. Patients with severe or very severe airflow limitations suffer a high number of distressing symptoms, such as shortness of breath, fatigue, dry mouth, and cough, and these patients are also frequently limited in their daily functions ${ }^{5-7}$. Symptom burden, a concept defined as the mean number of symptoms per patient and a composite measure of symptom frequency, severity and distress ${ }^{8}$, is associated with reduced physical, psychological and social functioning as well as decreased health-related quality of life ${ }^{5}$ Although symptoms serve as a focus for diagnoses and treatment of $\mathrm{COPD}^{1}$, most symptom knowledge is based on studies of patients with severe or very severe airflow limitations ${ }^{5,7,9}$. There is limited knowledge of the symptom experience in patients with moderate airflow limitation.

Symptoms, defined as "subjective experiences reflecting changes in the bio-psychosocial functioning, sensations or cognition of an individual," $" 10$ are conceptualized as multidimensional including the dimensions frequency, severity and distress that can be measured separately or in combination ${ }^{11}$. Earlier studies concerning symptom research and COPD have mostly been focused on a single symptom and/or a single dimension of a symptom $^{12-16}$, whereas studies using multidimensional symptom assessment have only included patients with advanced COPD ${ }^{5-7,17}$. 
Multidimensional assessment provides detailed information on both the prevalence and experience of symptoms, i.e., frequency, severity and distress, where even small changes in symptom experience can be detected ${ }^{18}$. The goal of symptom management is to reduce frequency, minimize severity, and relieve distress ${ }^{10}$. As there is no cure for COPD, symptom control is necessary for improvement of patients' health-related quality of life ${ }^{19}$, and nurses have a key role in symptom management as they are involved in all stages of care ${ }^{20}$. Recently, the GOLD guidelines highlighted the importance of symptom assessments ${ }^{1}$. Although the majority of patients with COPD are diagnosed with moderate airflow limitation ${ }^{3}$, to the best of our knowledge, no study has assessed multidimensional symptoms in this group of patients. Therefore, the aim of this study was to describe the multidimensional symptom profile in outpatients with stable COPD and to determine whether the symptom experience differed between patients with moderate and severe airflow limitations.

\section{METHODS}

\section{Design}

This research is part of a wider cross-sectional study with the purpose of describing symptoms, function and health among patients with stable COPD. The specific focus of the main study was to examine the experience of fatigue and its relationship to physical capacity and disease severity in men and women with $\mathrm{COPD}^{21}$. The study was conducted in accordance with the Declaration of Helsinki and was approved by the regional research ethics committee (Linköping, Sweden, Dnr M 121-06). All participants provided informed consent before participation. 


\section{Sample and Settings}

Patients were potentially eligible for recruitment if they had visited the pulmonary department at one university hospital or one county hospital the year before the study started. The inclusion criteria were that patients had been diagnosed with COPD (ICD-10 code J44) and were in a clinically stable condition with no change in medication for the previous four weeks. Patients were excluded if they had a serious coexisting medical condition (other lung disease, rheumatoid arthritis, cancer within the last five years, severe ischemic heart disease, renal failure, liver disease, insulin-dependent diabetes, stroke, or multiple sclerosis) or other difficulties that might interfere with the assessments. Eligibility was determined through the patient administrative system. Those who fulfilled the diagnostic criteria received a letter with a brief introduction to the study. One week later they were phoned by a member of the research group, who provided additional information and obtained informed consent. The patients who were willing to participate were offered an appointment at the outpatient clinic for assessment. Out of the 121 patients included in the main study, eight patients were not assessed for symptom experience. Due to the insufficient number of patients classified with mild $(n=6)$ and very severe air flow limitation $(n=16)$ this sample was limited to 91 patients with moderate and severe air flow limitation.

\section{Measurements}

The symptoms were assessed by using the Memorial Symptom Assessment Scale (MSAS) ${ }^{18}$, which was completed by the patients at the outpatient clinic. MSAS evaluates a multidimensional symptom profile, including the prevalence of 32 symptoms and the symptom experience of 26 physical and six psychological symptoms during the previous week. Symptom prevalence was recorded as yes $=1$ or no $=0$. Whenever a symptom was present, the symptom experience was assessed by the dimensions of frequency $(1=$ rarely to 4 
= almost constantly) for 24 symptoms, severity $(1=$ slight to 4 = very severe $)$, and distress $(0.8=$ not at all to $4.0=$ very much $)$ associated with all 32 symptoms during the preceding week. Higher scores indicate greater frequency, severity and distress. A score for each symptom, defined as an MSAS symptom burden score, was calculated by averaging the scores for frequency, severity and distress dimensions.

The MSAS has several subscales: the psychological (MSAS-PSYCH) subscale, which is the average symptom score of worrying, feeling sad, feeling nervous, difficulty sleeping, feeling irritable, and difficulty concentrating; the physiological (MSAS-PHYS) subscale, which is the average symptom score of lack of appetite, lack of energy, pain, feeling drowsy, constipation, dry mouth, nausea, vomiting, and changes in taste, weight loss, feeling bloated, and dizziness. The global distress index (MSAS-GDI) is the average score of 10 single dimensions, including the frequency of feeling sad, worrying, irritable, and nervous, and the distress scores of lack of appetite, lack of energy, pain, feeling drowsy, constipation and dry mouth. The MSAS total score (TMSAS) is the average score of all 32 symptoms with a range of $0-4^{18}$. The MSAS is a valid and reliable instrument to assess a multidimensional symptom profile and was originally developed to measure symptoms in patients with cancer but has lately been used on patients with chronic diseases ${ }^{5-7,17}$, including COPD. The MSAS was forward and backward translated from English into Swedish by native-speaking translators. To check ease of use, understanding of items and respondent burden, a feasibility study was performed that included 15 patients with COPD and 40 patients with cancer ${ }^{22}$.

The Cronbach's alpha coefficient in this study was as follows: MSAS-PHYS, 0.67; MSASPSYCH, 0.74; MSAS-GDI, 0.76; and TMSAS, 0.85. 


\section{Lung function}

A dynamic lung function test was performed (Master Scope $®$ Jaeger, Germany) in accordance with the ATS/ERS standardization ${ }^{23}$. To calculate the percentage of predicted values for $\mathrm{FEV}_{1}$ and $\mathrm{FVC}$, normative values from Hedenstrom et al. were used ${ }^{24,25}$. The severity of airflow limitation was defined according to the Global Initiative for Chronic Obstructive Lung Disease (GOLD) grading system ${ }^{1}$ as follows: GOLD 2: moderate airflow limitation $50 \% \leq \mathrm{FEV}_{1}, 80 \%$ predicted, GOLD 3: Severe airflow limitation $30 \% \leq \mathrm{FEV}_{1}, 50 \%$ predicted $^{1}$.

\section{Patient Characteristics}

Data on age, sex, current marital status, current employment, smoking habits and pack years of smoking, self-reported medical use, number of exacerbations during the last six months and hospital stay related to pulmonary disease during the previous year were collected by a questionnaire. Physical and emotional health during the previous month was assessed with two questions from the International Classification of Functioning, Disability and Health check list (ICF) of the World Health Organization (WHO 2001). The answer scores were from $5=$ Very good to $1=$ Very bad $^{26}$. The data collection was performed between January 2007 and September 2009.

\section{Data analysis}

Descriptive statistics were undertaken for patient characteristics, prevalence and experience of symptoms, and MSAS symptom burden score. Differences of symptom prevalence (present in $\geq 25 \%$ of the patients) and symptom experience (frequency, severity and distress) between patients with moderate and severe airflow limitations were analyzed by Chi-square or Fisher's exact test as appropriate, whereas differences of MSAS symptom burden score and MSAS subscales (MSAS-PHYS, MSAS-PSYCH, MSAS-GDI and TMSAS) were analyzed by using 
the Mann-Whitney U test. The MSAS symptom scores are presented as the mean (SD) for comparison with previous research, although the data are skewed. P-values were two-sided, and the significance level was set at $\mathrm{p} \leq 0.05$. Statistical analyses were conducted using PASW Statistics (SPSS) version 20.

\section{RESULTS}

In total, 91 patients assessed with MSAS met the criteria for moderate $(n=42)$ or severe airflow limitations $(n=49)$. Of those 91 patients, $47 \%$ were men, and $53 \%$ were women, with a mean age of $68( \pm 7)$ years for men and $67( \pm 8)$ years for women. The majority $(70 \%)$ of patients were married or cohabitating. In addition, $61 \%$ were retired, and $15 \%$ were on sick leave. Twenty-eight percent of the patients still smoked, and 69\% had stopped smoking. The mean BMI $\left(\mathrm{kg} / \mathrm{m}^{2)}\right.$ was $26.8( \pm 5.7)$.

There were no significant differences in demographic characteristics, smoking history or BMI between patients with moderate and severe airflow limitations (Table 1). A lower proportion of patients with moderate airflow limitation used inhalation treatment with glucocorticosteroids, long-acting $\beta_{2}$-agonists and short-acting $\beta_{2}$-agonists, but a higher proportion used analgesics compared with patients with severe airflow limitation.

\section{Symptom prevalence and symptom experience}

The patients reported multiple symptoms with a mean number of $7.9( \pm 4.3)$ symptoms $($ median $=7$, range $0-32)$ for the total sample, $8.1( \pm 4.4)$ for moderate airflow limitation and $7.7( \pm 4.3)$ for severe airflow limitation $(\mathrm{P}=0.36)$. Table 2 presents the symptom prevalence for the total sample and the symptom experience for patients classified with moderate and severe airflow limitations. Highly prevalent physical symptoms ( $\geq 50 \%$ of the total sample) were shortness of breath (90\%), cough (65\%), dry mouth (65\%), and lack of energy (55\%). Five additional physical symptoms, feeling drowsy, pain, numbness/tingling in hands/feet, 
feeling irritable and dizziness, were reported by between $25 \%$ and $50 \%$ of the patients. The most commonly reported psychological symptom was difficulty sleeping (52\%), followed by worrying (33\%), feeling irritable (28\%) and feeling sad (22\%). There were no significant differences in the occurrence of physical and psychological symptoms between patients with moderate and severe airflow limitations.

Among the patients with moderate airflow limitation, the top five most prevalent symptoms, shortness of breath, cough, dry mouth, lack of energy and difficulty sleeping, were reported to occur frequently or almost constantly by $28-45 \%$ of the patients, to be severe or very severe by $12-28 \%$ of the patients, and to be quite a bit or very much distressing by $21-38 \%$ of the patients. Among the patients with severe airflow limitation, the same symptoms were reported to occur frequently or almost constantly by $31-71 \%$ of the patients, to be severe or very severe by $4-30 \%$ of the patients, and to be quite a bit or very much distressing by $8-55 \%$ of the patients. In both groups, those proportions were lower than the proportions for prevalence of the symptoms. A comparison of symptom experience between patients with moderate and severe airflow limitation indicated that a lower proportion of patients with moderate airflow limitation reported the symptom of lack of energy with high frequency (frequently or constantly) and high distress (quite a bit or very much) than was the case for patients with severe airflow limitation. Patients with moderate airflow limitation also reported shortness of breath as occurring less frequently than patients with severe airflow limitation.

\section{MSAS symptom burden and subscales scores}

The six symptoms rated with the highest MSAS symptom burden score, mean $( \pm \mathrm{SD})$, in the whole sample were shortness of breath, $2.4( \pm 1.0)$; dry mouth, $1.6( \pm 1.4)$; cough, $1.4( \pm 1.1)$; sleep problems, $1.4( \pm 1.4)$; lack of energy, $1.3( \pm 1.3)$; and pain, $1.2( \pm 1.4)$. The mean $( \pm \mathrm{SD})$ 
MSAS symptom burden scores for moderate and severe airflow limitations are presented in table 3. Patients with moderate airflow limitation had significantly lower MSAS symptom burden scores for shortness of breath than patients with severe airflow limitation (table 3 ). No significant differences were found between patients with moderate and severe airflow limitations regarding the four MSAS subscales scores, i.e., MSAS-PHYS, MSAS-PSYCH, MSAS-GDI and TMSAS (table 4).

\section{DISCUSSION}

We conducted this cross-sectional study using MSAS to describe the multidimensional symptom profile in patients with stable COPD, and compare patients with moderate and severe airflow limitations. Although patients with moderate and severe airflow limitations have similar symptom prevalence, patients with severe airflow limitations experience greater frequency and burden of 'shortness of breath', and greater frequency and distress of lack of energy compared to patients with moderate airflow limitations. This implies that a multidimensional symptom assessment should be performed in all grades of airflow limitation and should include several symptoms rather than focusing only on disease-specific symptoms.

The patients in the present study had a mean number of 7.9 symptoms, with no difference between patients with moderate and severe airflow limitations. This is slightly lower than in patients with severe or very severe airflow limitations, ranging between 9-14 symptoms $5,6,17$,

${ }^{27}$. However, three symptoms that often occur in COPD - chest tightness, wheezing and sputum production - were not included in the present study ${ }^{28}$. If those symptoms had been added to the MSAS instrument, the total symptom prevalence might have been even higher. In addition, patients in this study were in a stable condition for at least four weeks, without 
severe comorbidity, and were living in their own homes, meaning the number of symptoms in this study was not overestimated. However, the MSAS symptom burden for the symptoms shortness of breath, cough, and dry mouth in our study were at almost the same levels as among patients with very severe airflow limitation ${ }^{5}$. The broad range of concurrent symptoms and a significant symptom burden for different symptoms in each group could define the patients in the present study as those suffering from high symptom burden. High symptom burden is associated with poor health among patients with COPD ${ }^{5}$. In the present study, patients with moderate airflow limitation did not differ in physical and mental health perception from those with severe. These findings indicate the importance of early identification and management of symptoms in patients with COPD. However, the high symptom burden among patients with moderate airflow limitation needs more attention, both in care and research, as these patients are usually identified and diagnosed when the disease has already significantly progressed ${ }^{1}$, and such patients are seldom separately evaluated to determine their multidimensional symptom experience. In terms of improving symptom management, it may be practical to start with multidimensional symptom assessment in all patients with COPD.

This study confirms that the predominant and most distressing symptom among patients with COPD is shortness of breath ${ }^{28 .}$ The high occurrence rates of shortness of breath are consistent with other studies using the MSAS scale ${ }^{5,6,17}$. Although there were no significant differences between patients with moderate and severe airflow limitations regarding the prevalence of shortness of breath, patients with moderate airflow limitation reported lower frequency and lower composite measure of MSAS symptom burden than those with severe airflow limitation. This indicates that multidimensional assessment of symptom experience is more 
appropriate to detect symptom burden than tools used for a simple assessment of the presence or absence of a symptom. As in this study, other studies have also demonstrated that poor lung function is associated with breathlessness but not with other symptoms ${ }^{29}$. Breathlessness is a "subjective experience of breathing discomfort" $" 30$ and can be missed by care professionals because of different barriers to help-seeking behaviors. A qualitative study including patients with moderate and severe airflow limitation found that patients experiencing breathlessness had low access to services because of the nature of the symptom development as well as patients' adaptation to restrictions with different activities, reaction from the social environment, and non-response from healthcare services ${ }^{31}$. Breathlessness is reported to be associated with other symptoms such as fatigue, slipping difficulties, pain, anxiety and depression $^{29}$. This makes it even more important to assess and treat breathlessness, not only in patients with severe but also in those with moderate airflow limitation.

Cough was ranked as the second most prevalent symptom. Chronic cough with sputum production is common and is often considered to be the first symptom of $\mathrm{COPD}^{32}$. Chronic cough is usually described only in terms of prevalence ${ }^{2,33}$. Patients with chronic cough have an increased risk of disease progression and exacerbations that might require hospitalization ${ }^{33}$, ${ }^{34}$. In this study, cough was reported by one-fifth of the patients with moderate airflow limitation as a highly distressing symptom. Patients with COPD need support and knowledge to manage and notice even small variations in change of frequency, severity and distress in cough, and thereby reduce the total symptom burden and avoid exacerbation.

Almost two-thirds of the patients in this study reported dry mouth, which might be explained by the high use of anticholinergic medication. Dry mouth is reported as a reversible adverse event ${ }^{35}$. Patients with moderate airflow limitation reported dry mouth as the most severe 
symptom but as the third most prevalent and distressing symptom. This indicates the importance of assessing the severity and distress of symptoms in clinical practice. Patients who are seriously bothered by dry mouth tend to change their food consumption behavior to ease their suffering ${ }^{36}$, which may lead to the risk of developing malnutrition. In clinical practice, nurses need to assess this problem in all patients with anticholinergic medication to prevent risk of altered food consumption, and should suggest treatment for dry mouth ${ }^{37}$.

Close to half of the patients in this study reported the symptom of lack of energy as prevalent, which is lower than in previous studies that included patients with severe or very severe airflow limitations ${ }^{5}$. There were no significant differences in the prevalence or symptom burden scores between the patients with different disease severity. The associations between experience of fatigue and lung function in earlier studies are contradictive. Bagaia-Ravary et al $^{38}$ showed that increased fatigue was not associated with airflow limitation, whereas Lewko et $\mathrm{al}^{39}$ reported higher fatigue scores for patients with severe airflow limitation. These differences may depend on the different methods used to assess the symptoms. Lack of energy or fatigue is negatively related to both health and function, leading to limitations in cognitive, physical and psychosocial functioning in patients with $\operatorname{COPD}^{40,41}$ and needs to be prevented and treated in all patients. In our study, lack of energy was the only symptom that displayed significantly lower frequency and distress associated with the symptom in patients with moderate airflow limitation than in those with severe. This reveals that there is a risk that distressing symptoms can be neglected whenever only the prevalence is assessed. A multidimensional symptom assessment may lead to a focus on more severe and distressing symptoms when planning patients' care. As lack of energy is a prevalent symptom early in the disease, longitudinal research is needed across the trajectory of the disease. 
Half of the study sample reported difficulties with sleeping, and there were no differences between patients with moderate and severe airflow limitation either in occurrence or experience of the symptom. This contradicts findings from a large European study reporting that as the severity of disease increased, so did the prevalence of night-time symptoms ${ }^{42}$. However, the disease severity in the aforementioned study was defined using a combination of symptomatic assessments and the patients' lung function classified according to GOLD guidelines ${ }^{1}$. Patients with mild to moderate airflow limitations are more likely to report insomnia and difficulty in initiating and maintaining sleep compared with the general population $^{43}$. Poor sleep is associated with lower quality of life in patients with severe airflow limitation ${ }^{44}$. However, patients with COPD report that support from healthcare providers is rare concerning sleeping difficulties ${ }^{45}$. Multiple symptoms are known to catalyze and negatively affect each other ${ }^{11}$ and thereby affect the quality of sleep ${ }^{46,47}$. Night-time symptoms and sleep disturbance are still "forgotten" dimensions in patients with COPD ${ }^{48}$ that need more attention in care and research.

Pain was a common symptom in our study as in others ${ }^{5,17,46}$ with no difference between those with moderate and severe airflow limitations. Close to one-fourth of the patients in each group reported that pain was quite a bit or very much distressing, but more patients with moderate airflow limitation used analgesics than those with severe. Studies have indicated that the prevalence of pain in the general population above 65 years ranges from 20 to $46 \%$ and that the most common sites of pain are back pain, pain in the knee or hip or other joints ${ }^{49}$. In this study, we did not ask specifically about pain connected to COPD disease, but recent studies ${ }^{50}$ have indicated that COPD patients experience more pain than healthy people of similar age. Specific COPD-related pain is localized to the neck and trunk and has been proven to interfere 
with daily activities ${ }^{50}$. These and other symptoms require adequate assessment and effective treatment to prevent ongoing suffering.

\section{Limitations}

The limitations in this study include the small sample size and the analysis of multidimensional symptom profile in patients only with moderate and severe airflow limitation. As this is a part of a study with few patients with mild and very severe airflow limitation (GOLD grade I and IV), there is a need for a larger study comparing all GOLD grades. Most patients in early GOLD grades (mild and moderate airflow limitations) are cared for in primary care. The patients included in this study were all recruited from pulmonary departments at two hospitals and might not necessarily be a representative sample of all patients with moderate and severe airflow limitations, but the results ought to be transferable to patients in a similar context.

In this study, we recruited only patients with stable COPD and without other serious coexisting medical condition, and this can be considered as a study strength, as some of the patients who were more symptomatic because of other diseases may have been excluded. Still, patients in this study might have had conditions that added to the total symptom burden. We know from other studies' that approximately $60 \%$ of patients with chronic respiratory disease have co-morbidity or multimorbidity ${ }^{4}$.

The MSAS instrument was developed to measure symptoms in patients diagnosed and treated for cancer ${ }^{18}$ and may miss some COPD-related symptoms. After our study was planned and started, the MSAS was tested for patients with COPD, and disease-specific symptoms were included $^{6}$; an approach which should be adopted in future studies. 
The impact of concurrent symptoms must be recognized in clinical practice in order to reduce the total symptom burden in patients at all grades of the disease. A multidimensional assessment provides detailed knowledge that is useful when planning and evaluating symptom management. These findings demonstrate that there is an unmet need for early management. One implication for future research would be to explore the occurrence of symptom clusters in patients with COPD. Studies have suggested that the occurrence of multiple symptoms frequently leads to the occurrence of symptom clusters ${ }^{51}$. These symptom clusters might be more important to explore rather than individual symptoms, especially when it comes to determining the impact on outcomes ${ }^{52,53}$.

\section{CONCLUSIONS}

The high prevalence of physical and psychological symptoms in patients with moderate, as well as severe airflow limitations indicates a need for early identification and symptom management in patients with COPD. The multidimensional assessment of symptom experience should be an important priority in the care of patients with COPD, with the purpose of focusing on severe and distressing symptoms in order to improve symptom management and reduce symptom burden progression.

\section{CONFLICT OF INTEREST STATEMENT}

We hereby confirm that no conflicts of interest are associated with this publication. All authors have made substantial contributions to this study regarding design, data analysis and critical revision. We confirm that the manuscript has been read and approved by all authors named in the manuscript, and no significant financial support for these studies has influenced 
its outcome. We confirm that ethical approval has been obtained and is acknowledged within the manuscript.

Funding statement: Funded, Medical Research Council of Southeast Sweden and the Swedish Heart and Lung Association, County Council of Ostergotland and Faculty of Health sciences, Linkoping University.

\section{Contribution:}

Study Design: MU, PJ, MK, KTo, ES, KTh.

Analysis: JE, MU, KTh.

Manuscript preparation: JE, MU, KTh. All authors performed a critical revision of the manuscript and approved the final version to be published

\section{References}

1. Vestbo J, Hurd SS, Agusti AG, Jones PW, Vogelmeier C, Anzueto A, et al. Global strategy for the diagnosis, management, and prevention of chronic obstructive pulmonary disease: GOLD executive summary. Am J Respir Crit Care Med 2013;187:347-65.

2. Lindberg A, Larsson LG, Ronmark E, Jonsson AC, Larsson K, Lundback B. Decline in FEV1 in relation to incident chronic obstructive pulmonary disease in a cohort with respiratory symptoms. Copd 2007;4:5-13. Epub 2007/03/17.

3. Lindberg A, Bjerg A, Ronmark E, Larsson LG, Lundback B. Prevalence and underdiagnosis of COPD by disease severity and the attributable fraction of smoking Report from the Obstructive Lung Disease in Northern Sweden Studies. Respir Med 2006;100:264-72. Epub 2005/06/25.

4. O'Kelly S, Smith SM, Lane S, Teljeur C, O'Dowd T. Chronic respiratory disease and multimorbidity: prevalence and impact in a general practice setting. Respir Med 2011;105:236-42. Epub 2010/08/19.

5. Blinderman CD, Homel P, Andrew Billings J, Tennstedt S, Portenoy RK. Symptom Distress and Quality of Life in Patients with Advanced Chronic Obstructive Pulmonary Disease. J Pain Symptom Manage 2009;38:115-23.

6. Jablonski A, Gift A, Cook KE. Symptom assessment of patients with chronic obstructive pulmonary disease. West J Nurs Res 2007;29:845-63.

7. Tranmer JE, Heyland D, Dudgeon D, Groll D, Squires-Graham M, Coulson K. Measuring the symptom experience of seriously ill cancer and noncancer hospitalized patients near the end of life with the Memorial Symptom Assessment Scale. J Pain Symptom Manage 2003;25:4209. 
8. Zambroski $\mathrm{CH}$, Moser DK, Bhat G, Ziegler C. Impact of symptom prevalence and symptom burden on quality of life in patients with heart failure. European journal of cardiovascular nursing : journal of the Working Group on Cardiovascular Nursing of the European Society of Cardiology 2005;4:198-206.

9. Walke LM, Gallo WT, Tinetti ME, Fried TR. The burden of symptoms among communitydwelling older persons with advanced chronic disease. Arch Intern Med 2004;164:2321-4.

10. Dodd M, Janson S, Facione N, Faucett J, Froelicher ES, Humphreys J, et al. Advancing the science of symptom management. J Adv Nurs 2001;33:668-76. Epub 2001/04/12.

11. Lenz ER, Pugh LC, Milligan RA, Gift A, Suppe F. The middle-range theory of unpleasant symptoms: an update. Advances in Nursing Science 1997;19:14-27.

12. Iley K. Improving palliative care for patients with COPD. Nurs Stand 2012;26:40-6. Epub 2012/07/14.

13. Theander $\mathrm{K}$, Unosson $\mathrm{M}$. Fatigue in patients with chronic obstructive pulmonary disease. J Adv Nurs 2004;45:172-7. Epub 2004/01/07.

14. Theander K, Unosson $M$. No gender differences in fatigue and functional limitations due to fatigue among patients with COPD. J Clin Nurs 2011;20:1303-10.

15. Caroci ADS, Caroci ADS, Lareau SC. Descriptors of dyspnea by patients with chronic obstructive pulmonary disease versus congestive heart failure. Heart \& Lung 2004;33:102-10.

16. Borge CR, Borge CR, Wahl AK, Moum T. Pain and quality of life with chronic obstructive pulmonary disease. Heart \& Lung 2011;40:e90-e101.

17. Bausewein C, Booth S, Gysels M, Kuhnbach R, Haberland B, Higginson IJ. Understanding breathlessness: cross-sectional comparison of symptom burden and palliative care needs in chronic obstructive pulmonary disease and cancer. Journal of Palliative Medicine 2010;13:1109-18. Epub 2010/09/15.

18. Portenoy RK, Thaler HT, Kornblith AB, Lepore JM, Friedlander-Klar H, Kiyasu E, et al. The Memorial Symptom Assessment Scale: an instrument for the evaluation of symptom prevalence, characteristics and distress. Eur J Cancer 1994;30A:1326-36. Epub 1994/01/01.

19. Burgel PR, Escamilla R, Perez T, Carre P, Caillaud D, Chanez P, et al. Impact of comorbidities on COPD-specific health-related quality of life. Respir Med 2013;107:233-41.

20. Fletcher MJ, Dahl BH. Expanding nursing practice in COPD: key to providing high-quality, effective, and safe patient care? Prim care respir J 2013;22:230-3. Epub 2013/05/15.

21. Tödt K, Skargren E, Kentson M, Theander K, Jakobsson P, Unosson M. Experience of fatigue, and its relationship to physical capacity and disease severity in men and women with COPD. Int J Chron Obstruct Pulmon Dis 2014;9:17-25.

22. Pettersson G, Berterö C, Unosson M, Börjeson S. Symptom prevalence, frequency, severity, and distress during chemotherapy for patients with colorectal cancer. Support Care Cancer 2013:1-9.

23. Brusasco V, Crapo R, Viegi G. Coming together: the ATS/ERS consensus on clinical pulmonary function testing. Eur Respir J 2005;26:1-2. Epub 2005/07/05.

24. Hedenstrom H, Malmberg P, Agarwal K. Reference values for lung function tests in females. Regression equations with smoking variables. Bull Eur Physiopathol Respir 1985;21:551-7. Epub 1985/11/01.

25. Hedenstrom H, Malmberg P, Fridriksson HV. Reference values for lung function tests in men: regression equations with smoking variables. Ups J Med Sci 1986;91:299-310. Epub 1986/01/01.

26. ICF Checklist BRIEF HEALTH INFORMATION [database on the Internet]. 2001.

27. Gift AG, Shepard CE. Fatigue and other symptoms in patients with chronic obstructive pulmonary disease: do women and men differ? Journal of Obstetrical Gynecology and Neonatal Nursing 1999;28:201-8. 
28. Rabe KF, Hurd S, Anzueto A, Barnes PJ, Buist SA, Calverley P, et al. Global strategy for the diagnosis, management, and prevention of chronic obstructive pulmonary disease: GOLD executive summary. Am J Respir Crit Care Med 2007;176:532-55. Epub 2007/05/18.

29. Borge CR, Wahl AK, Moum T. Association of breathlessness with multiple symptoms in chronic obstructive pulmonary disease. J Adv Nurs 2010;66:2688-700.

30. Meek PM, Schwartzstein RM, Adams L, Altose MD, Breslin EH, Carrieri-Kohlman V, et al. Dyspnea - Mechanisms, assessment, and management: A consensus statement. Am J Respir Crit Care Med 1999;159:321-40.

31. Gysels M, Higginson IJ. Access to services for patients with chronic obstructive pulmonary disease: the invisibility of breathlessness. J Pain Symptom Manage 2008;36:451-60.

32. Qaseem A, Wilt TJ, Weinberger SE, Hanania NA, Criner G, Van der Molen T, et al. Diagnosis and Management of Stable Chronic Obstructive Pulmonary Disease: A Clinical Practice Guideline Update from the American College of Physicians, American College of Chest Physicians, American Thoracic Society, and European Respiratory Society. Ann Intern Med 2011;155:179-92.

33. Miravitlles M. Cough and sputum production as risk factors for poor outcomes in patients with COPD. Respir Med 2011;105:1118-28.

34. Burgel PR, Nesme-Meyer P, Chanez $P$, Caillaud D, Carre P, Perez T, et al. Cough and sputum production are associated with frequent exacerbations and hospitalizations in COPD subjects. Chest 2009;135:975-82. Epub 2008/11/20.

35. Godara N, Godara R, Khullar M. Impact of inhalation therapy on oral health. Lung India 2011;28:272-5.

36. Quandt SA, Savoca MR, Leng X, Chen H, Bell RA, Gilbert GH, et al. Dry mouth and dietary quality in older adults in North Carolina. J Am Geriatr Soc 2011;59:439-45.

37. Reisfield GM, Rosielle DA, Wilson GR. Xerostomia, Second Edition \#182. J Palliat Med 2009;12:189-90.

38. Baghai-Ravary R, Quint JK, Goldring JJ, Hurst JR, Donaldson GC, Wedzicha JA. Determinants and impact of fatigue in patients with chronic obstructive pulmonary disease. Respir Med 2009;103:216-23.

39. Lewko A, Bidgood PL, Garrod R. Evaluation of psychological and physiological predictors of fatigue in patients with COPD. BMC pulmonary medicine 2009;9:47.

40. Theander K. Fatigue, functional status, health and pulmonary rehabilitation in patients with chronic obstructive pulmonary disease. Linköping: Linköping university; 2007.

41. Theander K, Jakobsson P, Torstensson O, Unosson M. Severity of fatigue is related to functional limitation and health in patients with chronic obstructive pulmonary disease. Int J Nurs Pract 2008;14:455-62.

42. Price D, Small M, Milligan G, Higgins V, Gil EG, Estruch J. Impact of night-time symptoms in COPD: a real-world study in five European countries. Int J Chron Obstruct Pulmon Dis 2013;8:595-603.

43. Valipour A, Lavie P, Lothaller H, Mikulic I, Burghuber OC. Sleep profile and symptoms of sleep disorders in patients with stable mild to moderate chronic obstructive pulmonary disease. Sleep Med 2011;12:367-72. Epub 2011/03/11.

44. Scharf SM, Maimon N, Simon-Tuval T, Bernhard-Scharf BJ, Reuveni H, Tarasiuk A. Sleep quality predicts quality of life in chronic obstructive pulmonary disease. Int J Chron Obstruct Pulmon Dis 2011;6:1-12. Epub 2011/02/12.

45. Shackell BS, Jones RC, Harding G, Pearse S, Campbell J. 'Am I going to see the next morning?' A qualitative study of patients' perspectives of sleep in COPD. Prim care respir J 2007;16:37883. Epub 2007/11/30. 
46. Bentsen SB, Gundersen D, Assmus J, Bringsvor H, Berland A. Multiple symptoms in patients with chronic obstructive pulmonary disease in Norway. Nurs Health Sci 2013;15:292-9. Epub 2013/01/29.

47. Lohne V, Heer HC, Andersen M, Miaskowski C, Kongerud J, Rustoen T. Qualitative study of pain of patients with chronic obstructive pulmonary disease. Heart Lung 2010;39:226-34. Epub 2010/05/12.

48. Agusti A, Hedner J, Marin JM, Barbe F, Cazzola M, Rennard S. Night-time symptoms: a forgotten dimension of COPD. European respiratory review : an official journal of the European Respiratory Society 2011;20:183-94.

49. Abdulla A, Adams N, Bone M, Elliott AM, Gaffin J, Jones D, et al. Guidance on the management of pain in older people. Age Ageing 2013;42 Suppl 1:i1-57.

50. HajGhanbari B, Holsti L, Road JD, Darlene Reid W. Pain in people with chronic obstructive pulmonary disease (COPD). Respir Med 2012;106:998-1005.

51. Dodd MJ, Miaskowski C, Lee KA. Occurrence of symptom clusters. Journal of the National Cancer Institute Monographs 2004:76-8.

52. Song EK, Moser DK, Rayens MK, Lennie TA. Symptom clusters predict event-free survival in patients with heart failure. Journal of Cardiovascular Nursing 2010;25:284-91.

53. Lee KS, Song EK, Lennie TA, Frazier SK, Chung ML, Heo S, et al. Symptom clusters in men and women with heart failure and their impact on cardiac event-free survival. J Cardiovasc Nurs 2010;25:263-72. 
Table 1. Background characteristics and use of medication for patients with stable chronic obstructive lung disease classified in patients with moderate and severe airflow limitation

Moderate Severe

$\mathrm{n}=42 \quad \mathrm{n}=49 \quad P$ value

Sex, n (\%) .607

Women

$19(45)$

$29(59)$

Men

$23(55)$

20(41)

Age (yrs), mean (SD)

$66.5(8,6)$

$67.9(6,8)$

.396

Married/ cohabitant n (\%)

29 (69)

$34(71)$

.854

Employed, n (\%)

7 (17)

7 (14)

Smoking, $\mathrm{n} \%$

Smoking

$13(31)$

$12(24)$

Former smokers

28 (67)

$35(71)$

Never smokers

$1(2)$

2 (4)

Pack years smoking, mean (SD)

$29.1(13.5)$

$34.0(19.5)$

.177

BMI $\left(\mathrm{kg} / \mathrm{m}^{2}\right)$, mean (SD)

$27.2(5.2)$

$26.5(6,1)$

.555

$\mathrm{FEV}_{1} \%$ of predicted, mean (SD)

$61.6(8.4)$

$42.2(5.8)$

$<.001$

$\mathrm{SpO}^{2} \%$ mean (SD)

$95.8(2.4)$

$94.5(3.0)$

.009

Physical health, mean (SD)

$3.0(0.8)$

.120

Mental health, mean (SD)

$3.7(0.9)$

$3.6(1.0)$

.628

Exacerbation previous 6 month, n (\%)

14(33)

$15(31)$

.781

Admitted to hospital previous year, $\mathrm{n}(\%)$

$10(24)$

14 (29)

.607

Medication use, $\mathrm{n}(\%)$

Inhaled glucocorticosteroids

Systemic glucocorticosteroids

Anticholinergic

Long-acting $\beta_{2}$-agonists

Short-acting $\beta_{2}$-agonists

Analgesics

Statins
$30(71)$

$3(6.3)$

32 (76)

$30(71)$

$13(31)$

$11(26)$

8 (19)
$44(90)$

.025

$0(0)$

.094

$42(86)$

.245

45 (92)

.011

$32(65)$

.001

5 (10)

.046

$11(23)$

Abbreviations: BMI: Body Mass Index, $\mathrm{FEV}_{1}$ : Forced Expiratory Volume in 1 second,

Pack years smoking: mean packs per day $\times$ years smoked. One pack year $=20$ cigarettes a day for one year

Moderate airflow limitation $50 \% \leq \mathrm{FEV} 1,80 \%$ predicted

Severe airflow limitation $30 \% \leq \mathrm{FEV} 1,50 \%$ predicted 
Table 2. Prevalence of physical and psychological symptoms for 91 patients with stable COPD and symptom experience for patients classified with moderate and severe airflow limitation

Symptom prevalence

Physical Symptoms

Shortness of breath

Cough

Dry mouth

Lack of energy

Feeling drowsy

Pain

Numbness/tingling in hands/feet

Sweats

Difficulty sleeping

Worrying

Feeling irritable
Dizziness

Psychological Symptoms

\begin{tabular}{|c|c|c|c|c|c|c|c|c|}
\hline & & & \multicolumn{2}{|c|}{ Frequency $^{\mathrm{a}}$} & \multicolumn{2}{|c|}{ Severity $^{\mathrm{b}}$} & \multicolumn{2}{|c|}{ Distress $^{c}$} \\
\hline $\begin{array}{l}\text { Total sample } \\
n=91\end{array}$ & $\begin{array}{l}\text { Moderate } \\
n=42\end{array}$ & $\begin{array}{l}\text { Severe } \\
n=49\end{array}$ & $\begin{array}{l}\text { Moderate } \\
n=42\end{array}$ & $\begin{array}{l}\text { Severe } \\
n=49\end{array}$ & $\begin{array}{l}\text { Moderate } \\
n=42\end{array}$ & $\begin{array}{l}\text { Severe } \\
n=49\end{array}$ & Moderate & $\begin{array}{l}\text { Severe } \\
n-49\end{array}$ \\
\hline $\mathrm{n}(\%)$ & $(\%)$ & $(\%)$ & $(\%)$ & $(\%)$ & $(\%)$ & $(\%)$ & $(\%)$ & $(\%)$ \\
\hline $82(90)$ & 85.7 & 93.9 & 45.2 & $71.4 *$ & 23.8 & 30.6 & 38.1 & 55.1 \\
\hline $59(65)$ & 69.0 & 61.2 & 28.6 & 30.6 & 16.7 & 4.1 & 21.4 & 8.2 \\
\hline $59(65)$ & 54.8 & 73.5 & 38.1 & 46.9 & 28.6 & 28.6 & 23.8 & 18.4 \\
\hline $50(55)$ & 50.0 & 59.2 & 16.7 & $36.7 *$ & 9.5 & 18.4 & 14.3 & $34.7 *$ \\
\hline $42(46)$ & 42.9 & 49.0 & 11.9 & 22.4 & 7.1 & 4.1 & 7.1 & 14.3 \\
\hline $40(44)$ & 50.0 & 38.8 & 33.3 & 20.4 & 11.9 & 10.2 & 28.6 & 24.5 \\
\hline $30(33)$ & 42.9 & 24.5 & 16.7 & 12.2 & 7.1 & 6.1 & 14.3 & 8.2 \\
\hline $26(28)$ & 26.2 & 30.6 & 4.8 & 12.2 & 4.8 & 12.2 & 4.8 & 12.2 \\
\hline $24(26)$ & 21.4 & 30.6 & 9.5 & 12.2 & 4.8 & 4.1 & 7.1 & 8.2 \\
\hline $47(52)$ & 47.6 & 55.1 & 28.6 & 38.8 & 14.3 & 20.4 & 23.8 & 28.6 \\
\hline $30(33)$ & 38.1 & 28.6 & 7.1 & 8.2 & 2.4 & 6.1 & 7.1 & 12.2 \\
\hline $25(27)$ & 28.6 & 26.5 & 9.5 & 4.1 & 2.4 & 4.1 & 7.1 & 2.0 \\
\hline
\end{tabular}

"Percentage of patients describing the frequency of the symptom as "frequent" or "almost constant."

b Percentage of patients describing the severity of the symptoms as "severe", or "very severe."

c Percentage of patients describing the distress associated with the symptom as "quite a bit", or " very much.", $\mathrm{N} / \mathrm{A}=$ Not Applicable,

Analyses performed with Chi-square or Fisher's exact test.

Only symptoms reported by $\geq 25 \%$ of the patients are included in this table.

$*$ = significance level set at $\mathrm{p} \leq 0.05$.

Symptom experience 
Table 3. Comparison of physical and psychological MSAS symptom burden score between patients with moderate and severe airflow limitation

\begin{tabular}{lll}
\multicolumn{3}{c}{ MSAS symptom burden score } \\
Moderate & Severe & $p$-value \\
$\mathrm{n}=42$ & $\mathrm{n}=49$ & \\
mean (SD) & mean (SD)
\end{tabular}

Physical Symptoms

Shortness of breath

$2.12 \pm(1.09)$

$2.58 \pm(0.90)$

0.02

Cough

$1.56 \pm(1.16)$

$1.24 \pm(1.06)$

0.22

Dry mouth

$1.38 \pm(1.42)$

$1.81 \pm(1.27)$

0.17

Lack of energy

$1.01 \pm(1.22)$

$1.53 \pm(1.37)$

0.10

Feeling drowsy

$0.82 \pm(1.04)$

$1.07 \pm(1.12)$

0.32

Pain

$1.35 \pm(1.46)$

$0.99 \pm(1.31)$

0.20

Numbness/tingling in hands/feet

$0.91 \pm(1.16)$

$0.53 \pm(1.03)$

0.07

$0.56 \pm(1.22)$

$0.49 \pm(1.17)$

0.78

Dizziness

$0.49 \pm(0.88)$

$0.74 \pm(1.20)$

0.43

Sweats

$0.47 \pm(0.96)$

$0.65 \pm(1.06)$

0.38

Psychological Symptoms

Difficulty sleeping

$1.26 \pm(1.44)$

$1.44 \pm(1.43)$

0.54

Worrying

$0.73 \pm(0.99)$

$0.71 \pm(1.17)$

0.68

Feeling irritable

$0.55 \pm(1.00)$

$0.52 \pm(0.94)$

0.88

The MSAS symptom burden score is the average of the frequency, severity and distress associated with each symptom.

Analyses performed with the Mann-Whitney U-test.

Only symptoms reported by $\geq 25 \%$ of the patients are included in this table. 
Table 4. Comparison of MSAS subscales scores between patients with moderate and severe airflow limitation

\begin{tabular}{llll} 
MSAS Subscales & Moderate $(\mathrm{n}=42)$ & Severe $(\mathrm{n}=49)$ & $\mathrm{p}$ value \\
\hline & Median $(\mathrm{min} / \mathrm{max})$ & Median $(\mathrm{min} / \mathrm{max})$ & \\
MSAS-PHYS & $0.52(0.0 / 1.72)$ & $0.58(0.0 / 1.97)$ & 0.36 \\
MSAS-PSYCH & $0.48(0.0 / 2.87)$ & $0.43(0.0 / 2.24)$ & 0.89 \\
MSAS-GDI & $0.66(0.0 / 2.56)$ & $0.72(0.0 / 1.98)$ & 0.52 \\
TMSAS & $0.55(0.5 / 1.54)$ & $0.50(0.0 / 1.93)$ & 0.94 \\
\hline
\end{tabular}

Abbreviation: MSAS-PHYS: The overall physical symptom score, MSAS-PSYCH: Psychological Symptom score, MSAS-GDI: The Global distress index, TMSAS; Total MSAS index score. 